\title{
Estresse e Estratégias de Enfrentamento em Mestrandos de Ciências da Saúde
}

\section{Stress and Coping Strategies of Master's-Level Health Sciences Students}

\author{
André Faro Santos*a,b \& Antônio Alves Júnior ${ }^{a}$ \\ ${ }^{a}$ Universidade Federal de Sergipe, Aracaju, Brasil, ${ }^{\mathrm{b}}$ Faculdade Pio Décimo, Aracaju, Brasil
}

\begin{abstract}
Resumo
A pesquisa objetivou conhecer a ocorrência de estresse em 27 mestrandos em ciências da saúde da Universidade Federal de Sergipe, sendo 16 mulheres e 11 homens. Buscou-se também delinear as estratégias de enfrentamento utilizadas para lidar com o estresse e os estressores percebidos na pós-graduação. Utilizou-se o Inventário de Sintomas de Stress para Adultos de Lipp, a Escala de Modos de Enfrentamento de Problemas e um questionário sobre possíveis estressores. Os resultados mostraram que 40,7\% dos sujeitos apresentaram estresse e houve associação entre estresse e sexo $(p<0,05)$, estando as mulheres mais vulneráveis ao mesmo. Verificou-se a associação entre o sexo e as principais estratégias de enfrentamento utilizadas pelos participantes que não tiveram estresse $(p<0,05)$, revelando a focalização no problema como uma estratégia mais freqüente para os homens. Acredita-se na importância de pesquisas que investiguem esta temática, pois o desempenho do mestrando pode ser influenciado pelo estresse experienciado na pós-graduação.

Palavras-chave: Estresse; pós-graduação; mestrado; enfrentamento.
\end{abstract}

\begin{abstract}
This research had the objective to examine the occurrence of stress among 27 master students of health sciences of the Universidade Federal de Sergipe [Federal University of Sergipe], of which 16 were women and 11 were men. And, it also sought to delineate the coping strategies used to deal with the stress and the stressors perceived by the graduate students. Lipp's Stress Symptoms for Adults Inventory, the Ways to Confront Problems Scale and a questionary about possible stressors were used. The results indicated that $40,7 \%$ of subjects had stress and that there was an association between stress and sex $(p<0,05)$, showing that women were more vulnerable to stress. The association between sex and the main coping strategies used by the participants that didn't have stress $(p<0,05)$ was verified, showing that focalizing on the problem was a more frequent strategy among men. We believe that more investigation on this topic is important, because the performance of master level students may be influenced by the stress during graduate education.

Keywords: Stress; graduate education; master’s degree; coping.
\end{abstract}

O estresse é uma resposta não específica do organismo diante de qualquer situação que ameace a homeostase do indivíduo, gerando a necessidade de mobilização para enfrentar o evento causador do desequilíbrio biopsicossocial (Selye, 1954). Considerado como um processo, o estresse tem por objetivo adaptar o organismo a uma condição externa ou interna que, de alguma forma, esteja alterando a percepção de bem-estar vivenciada pelo sujeito (Calais, Andrade, \& Lipp, 2003; Lazarus, 1999).

O estresse surge mediante um processo de etapas, nas quais a sintomatologia e a forma de manejo são diferenciadas de acordo com a fase observada (Lipp, 2003). Segundo o modelo de Lipp (2000), são quatro as fases do estresse: alarme, resistência, quase-exaustão e a exaustão. A distinção das mesmas se dá pela duração da ação do estressor e pelo aparecimento de sintomas orgânicos e/ ou psicológicos.

\footnotetext{
* Endereço para correspondência: Avenida Silvio Teixeira, 691/1402, Jardins, Aracaju, SE, 49025-100. Fone: (79) 3231-1734. E-mail: andrefaro@superig.com.br Agradecimentos à Prof. Dra. Maria Jésia Vieira e aos colegas mestrandos pelos grandes debates em aula.
}

A fase de alarme é considerada a resposta inicial do organismo ante o estressor, em que são desencadeadas uma série de reações fisiológicas para a sobrevivência, dentre elas o aumento da pressão arterial e a tensão muscular, dentre outras. Há também, como a faceta positiva do estresse na fase de alarme, uma elevação no nível de atenção e velocidade na articulação de pensamentos, além do aumento na motivação e disponibilidade para envolver-se em novos projetos. A fase da resistência acontece quando há a persistência do estressor, predominando a reação passiva na busca pela adaptação. Entre sintomas desta fase estão a hipertensão arterial, o isolamento social e os problemas de memória e atenção (Lipp, 2003).

A quase-exaustão caracteriza-se pelo início do enfraquecimento do organismo diante do estresse, podendo surgir doenças, mas ainda não tão graves quanto à fase de exaustão. A exaustão evidencia-se pela impossibilidade de resistência ao estressor e surgimento de patologias orgânicas e psíquicas, sendo que se o estressor permanece atuando, por um fracasso adaptativo, pode levar à morte. São patologias observadas nesta fase: doenças cardíacas, auto-imunes, síndrome de Burnout, depressão, dentre outras (Lipp, 2003). 
Segundo Lipp (2003), algum nível de estresse é sempre necessário; porém, quando ultrapassa a capacidade de adaptação do sujeito, pode tornar-se prejudicial ao funcionamento organismo. Assim, para alcançar o bom desempenho de suas atividades, o indivíduo precisa estar mobilizado para responder às demandas internas e externas que surgem em seu cotidiano, num nível de estresse compatível com suas possibilidades (Savóia, 1999). Há a necessidade de ser mantido o nível de estresse adequado para ser ter uma produtividade satisfatória para um dado momento, pois a evocação de maiores ou menores defesas em relação à percepção do evento possivelmente trará danos pela inadaptação ou falta de reatividade (Sardá, Legal \& Jablonsky Jr., 2004).

A fim de que seja compreendido o estresse, é necessário atentar-se aos eventos estressores que deflagram as reações adaptativas. Margis, Picon, Cosner e Silveira (2003) destacaram que os estressores podem ser delineados em três categorias: os macro-estressores, micro-estressores e os estados de tensão crônica. Macro-estressores são eventos específicos que ocorrem ao longo do curso da vida, podendo originar efeitos fisiológicos e psicológicos sob a forma de sintomas e desadaptação (ex. casamentos, divórcios, etc.). Os micro-estressores referem-se às situações cotidianas que geram estresse a partir do acúmulo de diversos eventos de menor porte (ex. engarrafamento, discussões conjugais, etc.). Os estados de tensão crônica são as experiências agressoras vividas através dos anos e que podem causar patologias graves ao longo da vida (ex. violência infantil, etc.) (Margis et al., 2003).

Os macro-estressores são os eventos estudados com maior freqüência, pois se constituem num acontecimento passível de delimitação, em que pode ser analisado o funcionamento das pessoas em relação ao estresse vivenciado. Quanto aos micro-estressores, torna-se difícil mensurar os seus efeitos de uma forma objetiva, já que depende do prisma único revelado pela pessoa. Contudo, seus efeitos podem ser observados através do constante incremento de novos estressores que, em algum momento, podem saturar a capacidade reativa do sujeito (Savóia, 1999).

Considerando-se a entrada na pós-graduação como uma situação particular que irá gerar a necessidade de diversos tipos de adaptação, concebe-se, neste estudo, o mestrado como um possível evento macro-estressor na vida do mestrando. Além disso, no cotidiano do mestrado também são configuradas demandas micro-estressoras que tendem a se acumular durante o período em que o estudante está envolvido com múltiplas atividades, dentro e fora da pósgraduação.

A produção científica do Brasil tem aumentado nas últimas décadas, alcançando, no ano 2002, o $17^{\circ}$ lugar no ranking mundial de Ciência e Tecnologia (Ministério da Ciência e Tecnologia, 2002). Diante desta realidade, a pósgraduação pode ser considerada como uma das grandes responsáveis por esta evolução (Guimarães \& Gomes, 2000).

Atualmente a pós-graduação brasileira strictu sensué dividida em dois níveis independentes, o mestrado e o douto- rado, tendo cada um duas etapas: a teórica e a confecção do trabalho final (Trzesniak, 2004). Martins (2000) comentou que a pós-graduação se apresenta como um dos setores nacionais que tem mostrado resultados positivos, ocupando uma posição estratégica no processo de modernização e progressão do desenvolvimento do país. Entretanto, para outros autores, diversos problemas são percebidos, tendo em vista da corrida pela ascensão internacional e a busca por maior produtividade científica.

Para Santos (2003), os mestrados no Brasil assumem características distintas a partir de sua alocação regional. O nível de rigor na produção científica dos mestrados varia de acordo com as possibilidades locais de continuação da formação na área acadêmica, chegando as exigências do mestrado a serem compatíveis com os critérios de avaliação dos doutorados no país. Este fato ocorre em vista da necessidade de realização de excelentes mestrados para sua própria manutenção e a concessão para a instalação de doutorados.

Voltarelli (2002) ressaltou que a produtividade acadêmica vem sendo um fator estressor para os pesquisadores nacionais. $\mathrm{O}$ autor apontou que a necessidade de dedicação exclusiva, sem um apoio financeiro significativo, a ênfase na publicação internacional e a concorrência desleal pela falta de estabilidade profissional do pesquisador podem levar a um estado de esgotamento mental, prejudicial à saúde do indivíduo. O estresse se insere neste panorama como um aspecto relevante na carreira acadêmica, tornando-se um fator que suscita atenção, embora não existam muitos estudos sobre a percepção dos pós-graduandos - os novos pesquisadores - em relação à pós-graduação (Pardo, Andrade, Santana \& Carvalho, 2004).

Os programas de pós-graduação no Brasil prevêem a realização de seminários como atividades que fazem parte dos cursos de mestrado e doutorado, cujo objetivo é induzir os estudantes ao início da pesquisa já no começo da pósgraduação, treinando a escrita, leitura da realidade pesquisada e a produção sistemática do documento final (Trzesniak, 2004). Por tratar-se de uma situação que possui uma demanda específica, o seminário pode caracterizar-se como um evento estressor focalizado, passível de estudo, o qual, se manejado de forma adequada, irá contribuir para a otimização do desempenho do mestrando. Caso contrário, pode configurar-se como um evento precipitador de um quadro de estresse prejudicial.

Visto as características que envolvem o estresse e a experiência com uma situação estressora, as formas pelas quais os indivíduos reagem ao estresse é um outro ponto importante de ser enfatizado, já que o evento estressor por si só não tem a capacidade de determinar o nível de estresse do sujeito; depende da avaliação e interpretação subjetiva que é dada ao estressor (Lazarus, 1999). O enfrentamento, que é uma resposta ao estresse, corresponde aos esforços cognitivos e comportamentais orientados para lidar com demandas externas ou internas que estejam excedendo ou sobrecarregando os recursos do sujeito. Entendidas como processo, as estratégias de enfrentamento podem ser aprendidas, usadas e des- 
cartadas, de acordo com a possibilidade de identificação e reforço num dado momento (Lazarus \& Folkman, 1984).

O objetivo das estratégias de enfrentamento é a redução, eliminação ou manejo do estresse mediante a avaliação que o indivíduo faz de um dado evento em sua vida (Antoniazzi, Dell'Aglio, \& Bandeira, 1998; Seidl, Tróccoli, \& Zannon, 2001). Se o enfrentamento for adequado, o estresse poderá ser reduzido e adequado ao momento; do contrário, pode chegar a intensificar o nível de estresse em vista da interpretação da situação (Lazarus \& Folkman, 1984). Nesta perspectiva, as respostas de enfrentamento tornam-se um foco de estudos para que sejam esclarecidos os comportamentos que são emitidos diante dos estressores e quais os seus efeitos no nível de estresse.

Tomando como problema a diversidade das respostas ao estresse, Lazarus e Folkman (1984) sugerem que o processo de enfrentamento pode ser compreendido a partir de aspectos mais globais, procurando assim estabelecer modelos teóricos que possam indicar a forma pela qual o indivíduo está respondendo à demanda estressora. $\mathrm{O}$ enfrentamento, segundo estes autores, possui duas funções básicas: o foco no problema e o foco na emoção. O primeiro busca modificar a relação da pessoa com o meio externo, enfatizando a demanda causadora do estresse. Já o segundo, focaliza a resposta emocional ao estressor, visando adequar a reação emocional. Quando o estressor mostra-se como passível de mudança ou superação, geralmente o foco no problema é mais utilizado. Entretanto, quando a situação já foi avaliada e, mesmo assim, são consideradas poucas possibilidades de mudança, o foco na emoção é mais provável de ser mobilizado (Antoniazzi et al., 1998; Savóia, 1999).

Alguns autores também sugeriram outras modalidades de resposta, destacando-se o suporte social e a religiosidade, como meios para lidar com um evento estressor (Seidl et al., 2001). Estes diversos tipos de enfrentamento não são mutuamente exclusivos, mesclando-se durante o contato com a situação estressora. Contudo, geralmente se observa que ocorre um quadro específico de ações e comportamentos que caracterizam a prevalência de uma ou outra forma de responder ao estresse, fato que surge como uma via de compreensão da maneira que o indivíduo está percebendo e reagindo ao estressor (Savóia, 1999).

Seguindo a perspectiva de Calais et al. (2003), entender como os estudantes percebem e lidam com as demandas estressoras da sua pós-graduação é uma possibilidade para que sejam empreendidas medidas de redução do estresse. Desse modo, torna-se relevante saber como se apresenta o processo de estresse e como ele é contex tualizado na pósgraduação, a fim de se conhecer qual o custo do desenvolvimento científico para a saúde dos novos pesquisadores, como também refletir sobre as possibilidades na promoção de qualidade de vida dos alunos que estão envolvidos na escalada da evolução científica brasileira.

Frente à realidade apresentada, esta pesquisa objetivou:

1. Conhecer a ocorrência do estresse em uma turma de mestrandos em ciências da saúde da Universidade Federal de Sergipe diante do primeiro seminário avançado.
2. Delinear o nível de estresse e as principais estratégias de enfrentamento adotadas.

3. Evidenciar os principais estressores percebidos pelos mestrandos no curso de pós-graduação.

\section{Método}

\section{Participantes}

A amostra foi composta por 27 mestrandos em ciências da saúde, sendo 11 do sexo masculino (40,7\%) e 16 do feminino $(59,3 \%)$. Predominou a faixa etária de 30 a 39 anos (48,1\%), seguida de 20 a 29 anos $(33,3 \%)$ e 40 a $49 \operatorname{anos}(18,6 \%)$. A formação profissional dos participantes foi: Medicina (25,9\%), Odontologia $(18,5 \%)$, Biomedicina (14,8\%), Enfermagem (14,8\%), Fisioterapia $(7,4 \%)$, Educação Física $(7,4 \%)$, Biologia $(7,4 \%)$ e Bioquímica $(3,8 \%)$. Encontrou-se o tempo médio de formação de 9,4 anos $(D P 6,68)$.

Dos entrevistados, $51,9 \%$ eram casados, $40,7 \%$ solteiros e 7,4\% estavam divorciados. A maioria dos mestrandos não tinha filhos (63\%). Quando à pretensão de prosseguir na formação acadêmica, $74,1 \%$ pretendem cursar um doutorado, uma pessoa afirmou não ter pensado na questão $(3,7 \%)$ e $22,2 \%$ relataram não ter interesse. Entre os mestrandos, $11,1 \%$ eram bolsistas e mantinham dedicação exclusiva para o mestrado, sendo que $88,9 \%$ trabalhavam durante o curso da pós-graduação.

O Mestrado em Ciências da Saúde do Núcleo de PósGraduação em Medicina da Universidade Federal de Sergipe foi escolhido por ser de caráter multidisciplinar, sugerindo diferentes modos de adaptação tanto em relação ao conteúdo das disciplinas, quanto à variedade na formação acadêmica dos docentes e dos colegas.

\section{Instrumentos}

Buscando-se identificar algumas das dificuldades do próprio aluno em relação ao fato de estar cursando a pós-graduação, relacionou-se sete fatores estressores, geralmente mencionados em pesquisas realizadas com esta temática, para que os estudantes indicassem quais eles percebiam em relação ao seu mestrado. São eles: relacionamento com os colegas, relacionamento aluno-orientador, relacionamento aluno-coordenação, falta de motivação, articulação do tempo para realizar o mestrado, aspectos financeiros da pesquisa e finanças pessoais. No último item dispôs-se de um espaço para que o aluno mencionasse alguma outra dificuldade não listada anteriormente.

Apresentou-se uma lista contendo 12 situações para que os mestrandos apontassem quais seriam as que causavam maior preocupação frente ao seu curso, podendo ser assinalado mais de um item dentre os citados. As situações foram elaboradas a partir da literatura consultada, sendo destacadas como freqüentes motivos de preocupação para os estudantes de pós-graduação. Foram elas: as apresentações orais, aproveitamento das supervisões, aproveitamento das disciplinas ofertadas, pouco contato com o orientador, dificuldade do tema escolhido para a pesquisa, possibilidade 
de não atingir o desempenho esperado pela banca, notas inferiores às esperadas, cobrança externa para a conclusão (bolsa, emprego, entre outras), pressão pelo bom desempenho (interna ou externa), questões financeiras por estudar e trabalhar simultaneamente, tempo para conclusão do mestrado e questões relativas ao calendário e horários das aulas. Deixou-se em aberto um último item, caso alguma situação que não fosse relacionada anteriormente pudesse ser indicada. Tanto as principais preocupações, como as principais dificuldades apontadas pelos mestrandos, foram obtidas através de freqüência percentual.

Para a mensuração do estresse, aplicou-se o Inventário de Sintomas de Stress para Adultos de Lipp (ISSL). O ISSL é composto por três quadros $(Q)$ que se referem às quatro fases do estresse, divididos de forma temporal em sintomas das últimas 24 horas $(Q 1-15$ sintomas da fase de alerta), última semana $\left(\mathrm{Q}^{2}-15\right.$ sintomas da fase de resistência e quase-exaustão) e último mês (Q3 - 23 sintomas da fase de exaustão). A sintomatologia é dividida em física e psicológica, correspondentes às manifestações mais freqüentes do estresse sentidas pelos indivíduos que vivenciam uma situação potencialmente estressora (Lipp, 2000).

No ISSL, o diagnóstico positivo é dado a partir da soma dos sintomas de cada quadro do inventário, sendo que ao ultrapassar o número limite em uma fase específica $(Q 1>$ 6; $\mathrm{Q}^{2}>3$ ou $>9 ; \mathrm{Q} 3>8$ ), isto indicará que a pessoa tem estresse, em qual fase ele se encontra e a sintomatologia predominante (Lipp, 2000).

Foi utilizada a Escala Modos de Enfrentar Problemas (EMEP), validada por Seidl et al. (2001), elaborada para conhecer as estratégias de enfrentamento mobilizadas pelos sujeitos que vivenciam uma situação de estresse. O instrumento é composto por 45 itens e possui quatro subescalas que expressam cognições (ações intrapsíquicas) e comportamentos (ações diretas) para lidar com eventos estressantes: focalização no problema (18 itens; á = 0,84), focalização na emoção ( 15 itens; á $=0,81$ ), busca de prática religiosa ( 7 itens; á $=0,74)$ e busca de suporte social $(5$ itens; á = 0,70). As respostas são dadas em uma escala tipo Likert de cinco pontos ( $1=$ Eu nunca faço isso; $2=$ Eu faço isso um pouco; $3=\mathrm{Eu}$ faço isso às vezes; $4=\mathrm{Eu}$ faço isso muito; 5 = Eu faço isso sempre). A EMEP permite evidenciar modalidades de enfrentamento a uma dada situação estressora, mostrando as estratégias utilizadas pelo sujeito a fim de reduzir, eliminar ou manejar as consequiências do estresse em relação a um estressor específico.

Os participantes foram instruídos mediante texto escrito, sendo efetuada uma adaptação do tex to sugerido por Seidl et al. (2001), o qual enfatiza um problema de saúde, a fim de ser aplicado à situação do primeiro seminário avançado. As instruções, após a adaptação, tiveram o seguinte conteúdo:

As pessoas reagem de diferentes maneiras a situações difíceis ou estressantes. Para responder a este questionário, pense sobre como você está lidando com o primeiro seminário avançado do mestrado, no momento atual. Concentre-se nas coisas que você faz, pensa ou sente para enfrentar as suas preocupações.
Em seguida era apresentado um exemplo e, assegurando-se da compreensão das instruções, o pesquisador comunicava que se afastaria enquanto o indivíduo estava respondendo a escala, retornando após o seu preenchimento. Decidiu-se por obter os resultados através do somatório dos valores assinalados na escala Likert, categorizando segundo as subescalas apontadas no estudo de Seidl et al. (2001). A maior média dos escores entre as quatro subescalas indicou qual a principal estratégia de enfrentamento utilizada pelo participante, conforme as orientações de E. M. F. Seidl (e-mail pessoal, 6 de junho de 2005).

A fim de conhecer a percepção dos alunos em relação a uma possível sensação de estresse diante da apresentação do seminário, formulou-se a pergunta "Neste momento, você se sente estressado por causa do seminário avançado?", tendo como respostas as alternativas sim e não. A elaboração desta questão, a qual se denominou de estresse autopercebido, se deu a partir da pesquisa realizada por Lopes e Faerstein (2001), em que os autores destacam que o relato verbal pode ser uma via para detecção de eventos vitais estressores e de um possível quadro de estresse, decorrente da experiência vivenciada pelos próprios sujeitos.

\section{Procedimentos}

A coleta dos dados foi realizada no primeiro seminário avançado, atividade em que os mestrandos apresentam parte de seu projeto de pesquisa aos pares e aos docentes da pósgraduação. Esta atividade permite identificar capacidades diversas, tais como: a habilidade para realizar apresentações orais, suscetibilidade a críticas, manejo adequado do tempo e a capacidade de abstração para a discussão das sugestões apresentadas pela platéia, dentre outras.

O seminário ocorreu durante dois dias, nos turnos da manhã e tarde. As apresentações foram distribuídas segundo a divisão por grupos de mestrandos, sendo que em média aconteciam sete apresentações por turno, com duração aproximada de 25 minutos, iniciando-se com a exposição do conteúdo e, em seguida, a apreciação dos professores. No momento da apresentação estavam presentes os outros pósgraduandos e, em média, quatro professores orientadores, estes que avaliavam e sugeriam modificações a serem realizadas no planejamento e execução da pesquisa.

Após ter assinado o termo de consentimento autorizando a realização da pesquisa e publicação dos resultados conforme a resolução $n^{\circ}$. 196/10/1996 do Conselho Nacional de Saúde, que estabelece os critérios éticos para pesquisas com seres humanos, cada mestrando respondeu aos instrumentos cerca de uma hora antes da sua apresentação no seminário avançado. O estudo foi aprovado pelo Comitê de Ética em Pesquisa com Seres Humanos da Universidade Federal de Sergipe (UFS).

\section{Análise dos Dados}

Para a análise dos dados descreveu-se a freqüência percentual das variáveis sócio-demográficas, da principal preocupação, do principal estressor e do estresse autopercebido, além da média e desvio padrão para as va- 
riáveis contínuas. Os dados foram analisados com o auxílio do programa SPSS 11.5, aplicando-se os testes do Qui-quadrado e o $t$ de Student para a verificação de relações estatísticas entre as variáveis de interesse e o diagnóstico de estresse. Os índices dos testes estatísticos foram considerados significativos quando $p<0,05$.

\section{Resultados}

Segundo os critérios de Lipp (2000), 40,7\% dos mestrandos apresentaram estresse. Dentre estes, 18,2 \% estavam na fase de alarme e $81,8 \%$ na fase de resistência (Figura 1), predominando sintomas físicos (63,6\%) e tendo em média nove sintomas ( $D P$ 7,27). Não foi detectado nenhum indivíduo nas fases de quase-exaustão e exaustão.

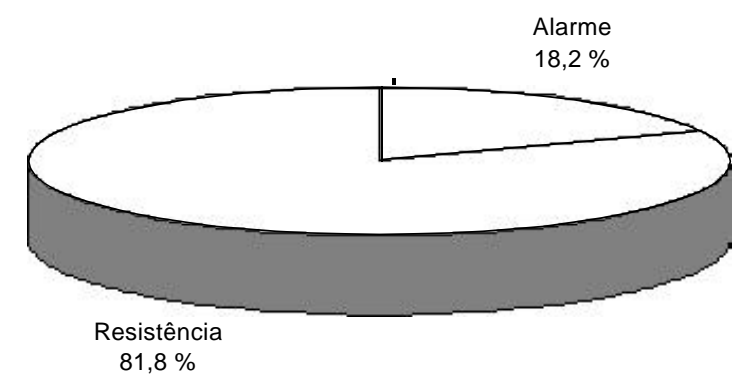

Figura 1. Fases do estresse diagnosticadas segundo os critérios do $\operatorname{ISSL}(n=11)$.
Analisando-se a ocorrência de estresse de acordo com o sexo, constatou-se que o feminino teve com maior freqüência o diagnóstico de estresse ( $81,8 \%$ ), ao contrário do masculino, onde 18,2\% apresentaram estresse (Figura 2). O teste do Qui-quadrado revelou uma associação significativa entre o diagnóstico de estresse e o sexo $(p<0,05)$, mostrando que de fato as mulheres foram mais estressadas na amostra geral. Quanto às demais variáveis (faixa etária, estado civil, filhos, pretensão de seguir para o doutorado e se trabalha durante o mestrado) não houve associação significativa $(p>0,05)$. Entre as variáveis tempo de formação e idade versus o diagnóstico de estresse, aplicou-se o teste $t$ de Student e não foi indicada diferença significativa $(p>0,05)$.

Quanto ao estresse autopercebido, 96,3\% dos participantes confirmaram sentir-se estressados e apenas uma pessoa disse não se perceber estressada (3,7\%). Com o teste Qui-quadrado não foi encontrado associação significativa entre o estresse autopercebido e o estresse na amostra global $(p>0,05)$.

A partir destes dados, pode-se concluir que, nesta amostra, as mulheres mostraram-se mais vulneráveis ao estresse, prevalecendo a fase de resistência, com sintomatologia física predominante e tendo alguma noção das repercussões do estresse em seu organismo.

O estressor mais freqüente foi a dificuldade na articulação do tempo para realizar o mestrado (38\%), seguido dos aspectos financeiros pessoais e da pesquisa $(26,2 \%)$ e da falta de incentivo e motivação (26,2\%). Ao serem delineadas as fontes de preocupação dos mestrandos, observou-se que as principais foram a possibilidade de não atingir o desempenho esperado pela banca (13,8\%), o aproveitamento das

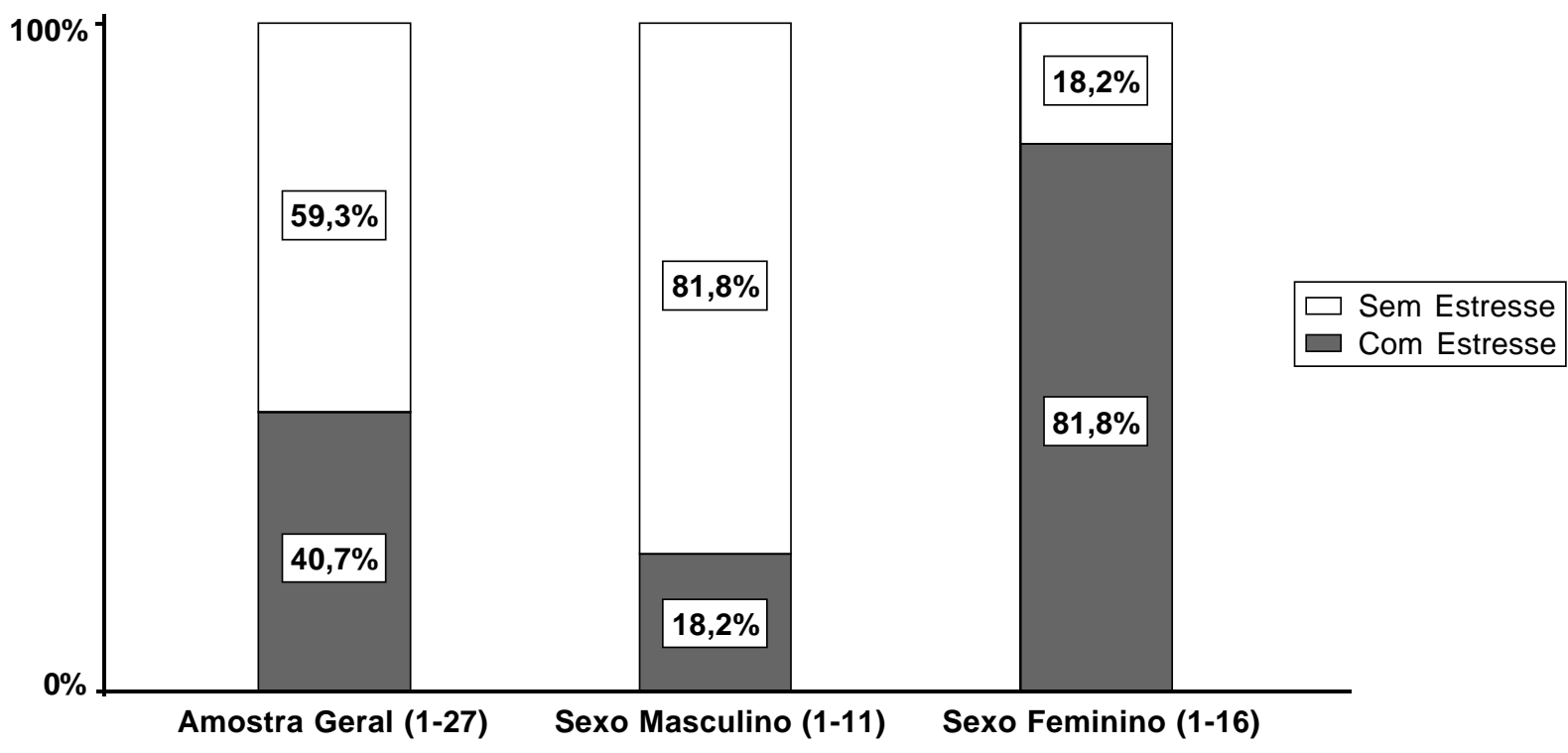

Figura 2. Distribuição da ocorrência do estresse na amostra geral e por sexo $(n=27)$. 
disciplinas ofertadas $(12,6 \%)$ e as questões relativas ao calendário e horários de aula (12,6\%) (Tabela 1).

Por ter havido o predomínio de mulheres entre os mestrandos que tiveram estresse e, por outro lado, dos homens entre os que não tiveram estresse, optou-se, na análise das estratégias de enfrentamento, agrupar os participantes segundo a ocorrência de estresse, também os separando de acordo com o sexo (Figura 3 ).

No grupo com estresse, os participantes do sexo masculino utilizaram principalmente o foco na emoção (50\%) e o suporte social (50\%), já o sexo feminino utilizou com maior freqüência o foco no problema (33,3\%) e o foco na emoção $(33,3 \%)$. Não foi constatada associação significativa entre o sexo e a principal estratégia de enfrentamento utilizada neste grupo $(p>0,05)$.
No grupo sem estresse, encontrou-se o predomínio do foco no problema junto ao sexo masculino $(66,7 \%)$ e, para o sexo feminino, o foco no problema $(42,9 \%)$ e o suporte social (42,9\%) sobressaíram-se como as principais modalidades de enfrentamento. O teste Qui-quadrado indicou associação significativa entre as variáveis sexo e estratégias de enfrentamento deste grupo $(p<0,05)$, confirmando que os homens que não tiveram estresse utilizaram com maior freqüência o foco no problema.

Em resumo, conclui-se que o foco no problema foi a estratégia mais utilizada pelos participantes que não tiveram estresse, principalmente para os homens, enquanto que no grupo com estresse não houve o predomínio de uma determinada estratégia de enfrentamento.

Tabela 1

Distribuição Percentual de Estressores e Preocupações Relativas à Pós-Graduação Apontados pelos Mestrandos ( $n=27)$

\begin{tabular}{lr}
\hline \multicolumn{1}{c}{ Estressores } & $\%$ \\
\hline Articulação do tempo & 38,0 \\
Aspectos financeiros pessoais e da pesquisa & 26,2 \\
Falta de incentivo e motivação & 26,2 \\
Relacionamento aluno-orientador & 4,8 \\
Distância da família & 2,4 \\
Relacionamento aluno-coordenação & 2,4 \\
Relacionamento com os colegas & 0 \\
\hline Total & 100 \\
\hline \multicolumn{1}{c}{ Preocupações } & $\%$ \\
\hline Possibilidade de não atingir o desempenho esperado pela banca & 13,8 \\
Aproveitamento das disciplinas ofertadas & 12,6 \\
Questões relativas ao calendário e horários das aulas & 12,6 \\
Apresentações orais & 10,3 \\
Pressão pelo bom desempenho & 10,3 \\
Questões financeiras por trabalhar e estudar simultaneamente & 9,1 \\
Tempo para conclusão do mestrado & 8,0 \\
Dificuldade do tema escolhido para a pesquisa & 6,9 \\
Cobrança externa para a conclusão & 4,6 \\
Pouco contato com o orientador & 4,6 \\
Aproveitamento das supervisões & 3,6 \\
Notas inferiores às esperadas & 3,6 \\
\hline Total & 100 \\
\hline
\end{tabular}

\section{Discussão}

Constatou-se a predominância do estresse no sexo feminino, manifestado principalmente por sintomas físicos. Outros autores já relataram que a ocorrência do estresse parece ser mais freqüente em mulheres (Calais, 2003; Calais et al., 2003; Lipp \& Tanganelli, 2002; Rocha \& DebertRibeiro, 2001; Sparrenberger, Santos, \& Lima, 2003).

Em relação ao processo saúde-doença, tem-se observado o crescimento da demanda das mulheres aos serviços de saúde, supondo que existe uma superposição de responsabilidades que não estão sendo adaptadas de modo salutar à qualidade de vida das mulheres (Rocha \& Debert-Ribeiro, 2001; Sparrenberger et al., 2003).

Rocha e Debert-Ribeiro (2001), em um estudo acerca das diferenças de gênero e estresse, detectaram que a divisão de trabalhos mantém-se dicotomizada entre o homem trabalhador externo e a mulher da casa, destacando que este aspecto acarreta um incremento de exigências, já que os cuidados com o lar e filhos continuam a ser direcionados para a mulher trabalhadora. Garduño e Márquez (1995) chamaram o conjunto dessas conseqüências como a "síndrome do estresse feminino", que pode desencadear 


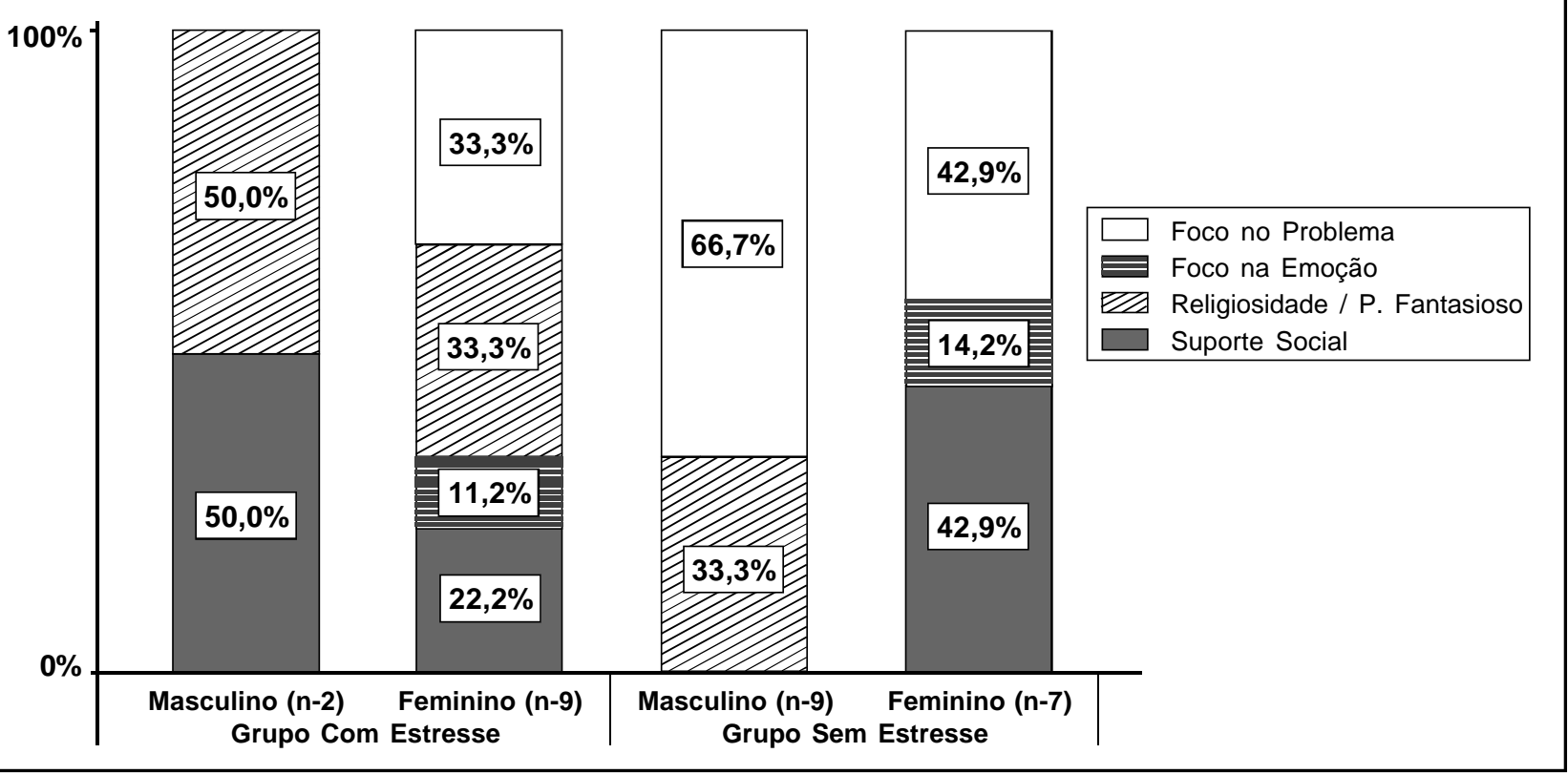

Figura 3. Principais estratégias de enfrentamento por sexo, segundo o diagnóstico de estresse $(n=27)$.

diversos problemas de saúde, tais como: diabetes, depressão, alcoolismo, infartos, isolamento social, etc.

Para alguns autores, o estudo sobre a prevalência do estresse feminino não é importante somente para as próprias mulheres, mas, devido ao papel de suporte emocional das mesmas para a família, torna-se relevante a implementação de ações que visem à redução e adequado manejo dos estressores no seu cotidiano, tendo em vista a saúde da própria mulher e, por extensão, da sociedade em geral (Calais et al., 2003; Garduño \& Márquez, 1995; Lipp \& Tanganelli, 2002).

Lipp e Tanganelli (2002) mencionaram como um possível contribuinte do estresse patológico das mulheres a sobrecarga de tarefas pela sua tripla jornada de trabalho, levando-as a despender maiores esforços para poder cumprir as suas funções regulares de esposa, mãe e profissional. $\mathrm{Na}$ presente pesquisa, em relação ao mestrado e as mulheres, pode-se destacar um panorama que se configura como uma quarta jornada, já que além de manter os referidos papéis existe o investimento no papel de mestrando, que possui suas exigências específicas.

A maioria dos mestrandos que apresentou estresse situou-se na fase de resistência, marcando as possíveis complicações derivadas deste diagnóstico. Esta fase caracterizase pelo cansaço físico, problemas de atenção e memória, insônia, hipersensibilidade e maior suscetibilidade a doenças infecciosas ou de caráter genético, além do comprometimento da produtividade devido aos sintomas que aparecem (Lipp \& Tanganelli, 2002). De acordo com tais achados, supõe-se que o seminário avançado constitui-se num evento estressor que mobilizou a necessidade de adaptação do mestrando para lidar com esta demanda. Ressalta-se que, em vista da situação específica do seminário, a capacidade de ter desempenho satisfatório é premente, visto que é um momento de avaliação do estudante em relação à evolução de seu pensamento científico e produção parcial da dissertação (Trzesniak, 2004).

Estando com estresse e na fase de resistência, o estudante pode apresentar um padrão inferior em relação ao que é possível de ser realizado, sendo assim, o manejo adequado do estresse e a caracterização dos estressores assumem destaque enquanto fatores que podem fomentar a eficiência do aluno.

Mesmo não denotando relevância estatística, é possível tomar-se como parâmetro os dados obtidos através da mensuração do estresse autopercebido, pois todos os indivíduos que apresentaram estresse perceberam-se estressados ao serem questionados como se sentiam. Um aspecto a ser salientado é o estresse autopercebido como um pedido de escuta, uma vez que os mestrandos sentiram-se "ameaçados" pela situação estressora. Sugere-se então que sejam criadas formas de ouvir estas demandas, visto que a sinalização de um estado além das possibilidades de enfrentamento - o estresse - fez-se falar na autoavaliação dos indivíduos.

Como os principais fatores estressores apontados pelos mestrandos, a articulação do tempo revelou-se como principal dificuldade. Bujdoso (2005), ao delinear os estressores percebidos por pós-graduandos, percebeu o tempo como uma dificuldade em relação aos prazos do mestrado. Zanella (2004) comentou que os mestrados possuem condições de produção que dificultam a capacidade de inovação e alcance dos objetivos esperados no final de uma pesquisa. Para essa autora, os prazos exíguos, a duração do mestrado e as diversas fontes de pressão comprometem a criatividade, que é uma prerrogativa da pós-graduação. 
Quando questionados sobre as principais preocupações, encontrou-se que a possibilidade de não atingir o desempenho esperado pela banca, aproveitamento das disciplinas, calendário e horário de aulas são os pontos que mais mobilizam os alunos. Sendo assim, a produtividade e a qualidade dos trabalhos produzidos são aspectos implícitos quando fica ressaltado o tempo como estressor. A ânsia por ter um desempenho satisfatório contrapõe-se às limitações para dedicar-se com maior afinco à pós-graduação e ainda manter-se financeiramente durante o seu curso (Voltarelli, 2002; Zanella, 2004).

Também é possível analisar algumas das exigências do mestrado como possuindo uma demanda subjacente, comentada por Santos (2003) quando ressaltou que talvez existam contradições nas expectativas acerca dos mestrandos, sobre o que eles podem e/ou devem produzir enquanto iniciantes na carreira acadêmica. As instituições que desejam consolidar-se como pós-graduação e, assim, serem autorizadas a ofertar doutorados, por vezes estabelecem critérios de avaliação em nível de teses, ainda que formalmente o estudo pretendido esteja categorizado como uma dissertação.

A importância que assume a concessão para a criação de doutorados gera uma sobreposição de objetivos institucionais que pode acarretar, para o pós-graduando, a solicitação implícita de que realize a sua dissertação seguindo os parâmetros esperados para um doutoramento. Neste último, o prazo para confecção do relatório final ea experiência anterior dos doutorandos, que em geral cursaram um mestrado, podem ser características importantes quando se compara o prazo para conclusão e o instrumental anterior do mestrando em relação ao desenvolvimento de sua pesquisa. Neste sentido, já a partir do mestrado pode configurar-se a corrida pela produtividade acadêmica, citada por Voltarelli (2002) como um fator estressor na vida do pesquisador, pois nem sempre os recursos, individuais e institucionais são capazes de atender a esta realidade.

Destaca-se que, por outro lado, o relacionamento com os colegas não foi referenciado como estressor. Bujdoso (2005) encontrou que a competitividade era um aspecto que problematizava o relacionamento interpessoal entre os mestrandos, dado não evidenciado nesta pesquisa. No mestrado em ciências da saúde, talvez a multidisciplinaridade dos alunos seja um fator minimizador da rivalidade que possa existir entre os mesmos. Havendo várias profissões dentro da realidade desta pós-graduação, a diversidade pode favorecer ao estabelecimento de uma rede de suporte social recíproca, potencializando ganhos pelo aprendizado mútuo e tornando menor a onipotência do "saber" profissional individual.

No tocante ao enfrentamento, notou-se que a focalização no problema foi a principal estratégia utilizada pelo grupo que não teve estresse, principalmente para os homens. $\mathrm{O}$ achado mostra que este tipo de enfrentamento auxiliou os mestrandos a lidarem com a demanda estressora, favorecendo a adaptação à situação. Também se sobressaiu o fato de que o sexo masculino predominou no grupo sem estresse, reforçando a associação encontrada na presente pesquisa em que as mulheres apresentaram maior vulnerabilidade ao estresse, não sendo igualmente eficaz a focalização no problema para essas.

Para Lazarus (1999), o impacto que um dado evento tem diante da capacidade de reação do indivíduo será determinado pela interpretação que o sujeito faz da situação. Nesse sentido, o enfoque pode ser voltado para a interpretação que é feita da situação, revelando por qual(is) perspectiva(s) as pessoas estão dimensionando a experiência estressante que vivenciam.

Malagris (2003) citou que fatores de personalidade influenciam as escolhas por determinadas estratégias de enfrentamento e na ocorrência do estresse, visto que pode haver uma predisposição para perceber situações como estressoras e manifestar respostas prontas para lidar com novas experiências. Outros estudos sugerem que há diferenças entre os gêneros e a manifestação de determinadas estratégias de enfrentamento. Nos homens é favorecida, historicamente, a focalização do problema e a tentativa de controle da situação estressora; já nas mulheres, existe a motivação cultural para perceber e expressar com maior facilidade as emoções, tendendo a lidar com o estresse de forma introspectiva e voltada para o suporte social (Antoniazzi et al., 1998; Calais, 2003; Zakir, 2003).

Com o conhecimento da percepção dos mestrandos acerca de sua pós-graduação, sugere-se que é possível o manejo de alguns fatores estressantes, abrandando a sobrecarga de determinadas situações e favorecendo a qualidade de vida na perspectiva dos comportamentos de saúde do aluno (Seidl \& Zannon, 2004). Seguindo a concepção sistêmica de Von Bertalanffy, a intervenção em uma das faces de um sistema desequilibrado incitará mudanças nas demais e, consequentemente, no sistema total (Calil, 1987). Para o estudante, a redução do estresse no mestrado pode influenciar no seu nível geral de estresse e assim promover a sua saúde, estando ou não no papel de pós-graduando.

Deste modo, fica ressaltada a importância de se estudar as diferenças entre os sexos em relação ao estresse, visto que os resultados mostraram que há estresse e que existiu uma dada estratégia eficaz na sua redução para o sexo masculino, mas não para o feminino. Sugere-se, a partir de tais achados, que fatores personológicos talvez estejam como variáveis intervenientes, já que as formas pela quais as pessoas percebem, avaliam e dão um significado ao estressor é um dos pontos-chave quanto ao aparecimento do estresse.

Como propostas para reflexão acerca da realidade pesquisada, um ponto a ser destacado é a flexibilidade dos indivíduos diante do estresse. Zakir (2003), em um estudo sobre controlabilidade pessoal, destacou que a presença do estresse excessivo esteve associada a estratégias de enfrentamento cristalizadas, o que gerava a falta de alternativas para que o indivíduo lidasse de forma mais adaptativa com o seu estresse. Logo, uma intervenção que pode ser incentivada é a criatividade dos pós-graduandos diante dos seus estressores, possibilitando a estruturação de novas ou diferentes estratégias de enfrentamento, mais adequadas às possibilidades do indivíduo em sua realidade (Alencar, 2002; Zanella, 2004). 
A análise da realidade percebida pelos mestrandos seria um passo inicial a ser dado na busca pela reorganização criativa da pós-graduação. À medida que crenças e costumes cotidianos - cujo impacto estressor é percebido nos momentos de crise - forem discutidos objetivando uma nova estrutura, poderão ser atenuadas as reações ao estresse sentidas pelos sujeitos. Como destacado por Zanella (2004), para a transformação criativa “. . . a capacidade analítica que permita desvendar essas amarras e produzir estratégias de enfrentamento é imperiosa" (p. 140), com a ressalva de que nesta mudança estejam implicadas as múltiplas dimensões envolvidas; dos docentes e alunos, à instituição.

Em relação ao tempo como estressor, vê-se que este é um ponto que não só atormenta os alunos, mas também orientadores e coordenações de pós-graduação (Bujdoso, 2005; Santos, 2003; Trzesniak, 2004; Zanella, 2004). Propõe-se que o diálogo sobre as demandas particulares dos envolvidos, mostrando suas limitações e, principalmente, propondo soluções, pode promover a adequação das necessidades de forma menos desgastante e mais produtiva.

Trzesniak (2004) citou que uma característica da carreira do pesquisador é a solidão na produção de seus trabalhos. Acredita-se que este fator torna-se mais crítico no papel de aluno, podendo gerar mais um estressor na produção de conhecimento, visto que seu instrumental cognitivo para pesquisa ainda está em formação. Como possibilidade de mudança, é possível refletir sobre o incentivo ao suporte social para lidar com esta característica. Para Zakir (2003) o suporte social depende mais do contexto externo do que outros tipos de estratégia de enfrentamento, já que o meio tem que fornecer os subsídios necessários ao sujeito e este, por sua vez, ver-se como carente de informação e apoio. No mestrado, o nível de disponibilidade dos docentes pode favorecer a este critério, priorizando a apreciação das dificuldades e busca de soluções conjuntas, formando a parceria entre um ex-mestrando e um novo pesquisador.

Como limitações observadas nesta pesquisa, o tamanho reduzido da amostra pode ter dificultado a exploração mais fidedigna da realidade, sendo interessante, em futuras pesquisas, a ampliação para outros mestrados e a execução em diferentes etapas do curso, visando uma melhor compreensão do estresse no contexto da pós-graduação.

Concorda-se com Alencar (2002) quando ressaltou que “... se os indivíduos se percebem e se avaliam como competentes, capazes e criativos, são mais propensos . . . a sentirem-se mais confiantes para expressar idéias e exibir comportamento criativo" (p. 68-69). O enfoque na redução do estresse promove uma reação em cadeia através de sua repercussão dentro e fora do mestrado, pautada na saúde do sujeito em vista da saúde da sociedade.

Enfim, a ênfase no estudo das demandas internas e externas do aluno de pós-graduação mostra-se relevante para novas pesquisas, a fim de que se possa delinear com mais clareza esta realidade e ser dissipada a crença, ainda infantil, de que a relação estudo-sofrimento são variáveis dependentes e que o conhecimento somente se alcança no decurso de um martírio; o estresse prejudicial.

\section{Referências}

Alencar, E. M. L. S. (2002). O estímulo à criatividade em programas de pós-graduação segundo seus estudantes. Psicologia: Reflexão e Crítica 15(1), 63-69.

Antoniazzi, A. S., Dell'Aglio, D. D., \& Bandeira, D. R. (1998). $\mathrm{O}$ conceito de coping. Uma revisão teórica. Estudos de Psicologia (Natal), 3(2), 273-294.

Bujdoso, Y. L. V. (2005). Dissertação como estressor: Em busca do seu significado para o mestrando em Enfermagem. Dissertação de Mestrado não-publicada, Faculdade de Medicina, Universidade de São Paulo, SP. Retirado em 16 set. 2005, do Banco Digital de Teses e Dissertações, de http://www.teses.usp.br

Calais, S. L. (2003). Diferenças entre homens e mulheres na vulnerabilidade ao stress. In M. E. N. Lipp (Ed.). Mecanismos neuropsicofisiológicos do stress: Teoria e aplicações clínicas. (pp. 8790). São Paulo, SP: Casa do Psicólogo.

Calais, S. L., Andrade, L. M. B., \& Lipp, M. E. N. (2003). Gender and schooling differences in stress symptoms in young adults. Psicologia: Reflexão e Crítica 16(2), 257-263.

Calil, V. L. L. (1987). Terapia familiar e de casal: Introdução às abordagens sistêmica e psicanalítica. São Paulo, SP: Summus.

Garduño, M. A., \& Márquez, M. S. (1995). El estrés en el perfil de desgaste de las trabajadoras. Cadernos de Saúde Pública 11(1), 65-81.

Guimarães, J. A., \& Gomes, J. (2000). Pós-Graduação 2001: Desempenho, perspectivas, desafios e riscos. INFOCAPES - Boletim informativo da CAPES, 8(4), 6-29.

Lazarus, R. S. (1999). Stress and emotion. New York: Springer.

Lazarus, R. S., \& Folkman, S. (1984). Stress, appraisal and coping. New York: Springer.

Lipp, M. E. N. (2000). Manual do inventário de sintomas de stress para adultos. São Paulo, SP: Casa do Psicólogo.

Lipp, M. E. N. (2003). O modelo quadrifásico do stress. In M. E. N. Lipp (Ed.) Mecanismos neuropsicofisiológicos do stress: Teoria e aplicações clínicas (pp. 17-21). São Paulo, SP: Casa do Psicólogo.

Lipp, M. E. N., \& Tanganelli, M. S. (2002). Stress e qualidade de vida em magistrados da justiça do trabalho: Diferenças entre homens e mulheres. Psicologia: Reflexão e Crítica 15(3), 537-548.

Lopes, C. S., \& Faerstein, E. (2001). Confiabilidade do relato de eventos de vida estressantes em um questionário autopreenchido: Estudo pró-saúde. Revista Brasileira de Psiquiatria 23(3), 123-133.

Malagris, L. E. N. (2003). Influência da diátese personológica. In M. E. N. Lipp (Ed.), Mecanismos neuropsicofisiológicos do stress: Teoria e aplicações clínicas (pp. 71-74). São Paulo, SP: Casa do Psicólogo.

Margis, R., Picon, P., Cosner, A. F., \& Silveira, R. O. (2003). Relação entre estressores, estresse e ansiedade. Revista de Psiquiatria do Rio Grande do Sul, 25(Supl. 1), 65-74.

Martins, C. B. (2000). O ensino superior brasileiro nos anos 90. São Paulo em Perspectiva 14(1), 41-60.

Ministério da Ciência e Tecnologia. (2002). Artigos publicados em periódicos científicos internacionais indexados no Institute for Scientific Information (ISI) e participação percentual em relação ao total mundial, principais países, 2002. Brasília, DF: MCT. Retirado em 16 set. 2005, de http://www.mct.gov.br/estat

Pardo, M. B. L., Andrade, T. C., Santana, I. T. T., \& Carvalho, A. B. G. C. (2004). A formação em pesquisa segundo a opinião de alunos de um programa de pós-graduação da Universidade Federal de Sergipe. Revista Brasileira de Pós-Graduação, 1, 70-85.

Rocha, L. E., \& Debert-Ribeiro, M. (2001). Trabalho, saúde e gênero: Estudo comparativo sobre analistas de sistemas. Revista de Saúde Pública, 35(6), 539-547. 
Santos, C. M. (2003). Tradições e contradições da pós-graduação no Brasil. Educação, Ẽ Sociedade, 24(83), 627-641.

Sardá, J. J., Legal, E. J., \& Jablonsky, S. J., Jr. (2004). Estresse: Conceitos, métodos, medidas e possibilidades de intervenção. São Paulo, SP: Casa do Psicólogo.

Savóia, M. G. (1999). Escala de eventos vitais e de estratégias de enfrentamento (coping). Revista de Psiquiatria Clínica, 26, 56-67.

Seidl, E. M. F., Trócolli, B. T., \& Zannon, C. M. L. C. (2001). Análise fatorial de uma medida de estratégias de enfrentamento. Psicologia: Teoria e Pesquisa, $17(3)$, 225-234.

Seidl, E. M. F., \& Zannon, C. M. L. C. (2004). Qualidade de vida e saúde: Aspectos conceituais e metodológicos. Cadernos de Saúde Pública, 20(2), 580-588.

Selye, H. (1954). Stress, a tensão da vida. São Paulo, SP: Ibrasa.

Sparrenberger, F., Santos, I., \& Lima, R. C. (2003). Epidemiologia do distress psicológico: Estudo transversal de base populacional. Revista de Saúde Pública, 37(4), 434-439.
Trzesniak, P. (2004). Qualidade e produtividade nos programas de pós-graduação: A disciplina seminário de dissertação. Revista Brasileira de Pós-Graduação, 1, 111-125.

Voltarelli, J. C. (2002). Estresse e produtividade acadêmica [Editorial]. Revista Medicina Ribeirão Preto, 35(4), 451-454.

Zakir, N. S. (2003). Mecanismos de coping. In M. E. N. Lipp (Ed.), Mecanismos neuropsicofisiológicos do stress: Teoria e aplicações clínicas (pp. 93-98). São Paulo, SP: Casa do Psicólogo.

Zanella, A. V. (2004). Atividade criadora, produção de conhecimentos e formação de pesquisadores: Algumas reflexões. Psicologia \& Sociedade, 16(1), 135-145.

Recebido: 23/11/2005

$1^{a}$ revisão: 01/06/2006

Aceite final: 10/07/2006 